\section{Kidney \\ Blood Pressure Research}

Kidney Blood Press Res 2018;43:606-615

DOI: 10.1159/000489145

Published online: 24 April, 2018

Accepted: 12 April, 2018

This article is licensed under the Creative Commons Attribution-NonCommercial-NoDerivatives 4.0 InternaThis article is licensed under the Creative Commons Attribution-NonCommercial-NoDerivatives 4.0 Interna-
tional License (CC BY-NC-ND) (http://www.karger.com/Services/OpenAccessLicense). Usage and distribution tional License (CC BY-NC-ND) (http://www.karger.com/Services/OpenAccessLicense). Usage and dist
for commercial purposes as well as any distribution of modified material requires written permission.

Review

\title{
Urate-Lowering Agents in Asymptomatic Hyperuricemia: Role of Urine Sediment Analysis and Musculoskeletal Ultrasound
}

\author{
Davide Viggiano ${ }^{a, b}$ Giuseppe Gigliottic Gianfranco Vallone ${ }^{d} \quad$ Anna Giammarino $^{c}$ \\ Michelangelo Nigro ${ }^{c}$ Giovambattista Capasso ${ }^{a}$
}

aDept. Cardiothoracic Sciences, Univ. Campania "L. Vanvitelli", Caserta, 'Department of Medicine and Health Sciences, University of Molise, Campobasso, CU.O.C Nefrologia e Dialisi ASL SA, Ospedale L. M.SS. Addolorata, Eboli, SA, dDepartment of Pediatric Radiology, University Hospital Federico II, Naples, Italy

\section{Key Words}

Uric acid • Urate nephropathy • Rasburicase $\cdot$ Canagliflozin $•$ Chronic kidney disease

\begin{abstract}
Current urate-lowering therapy (ULT) includes three direct acting drugs (allopurinol, febuxostat, Rasburicase) and at least four 'indirect' drugs with other important targets (canagliflozin, losartan, fenofibrate and sevelamer). Moreover, the alcalinization of urines using bicarbonate can be used to dissolve urate crystals and the clinician may discontinue several drugs are known to increase serum levels of uric acid, such as diuretics, aspirin, cyclosporine, theophylline, mycophenolate and ACE inhibitors. While there is a consensus to start ULT in cases of symptomatic hyperuricemia (gout, urate-nephrolithiasis), the very frequent conditions of asymptomatic hyperuricemia remains a major conundrum. The effect of asymptomatic hyperuricemia on kidney function has had fluctuating positions over decades. The conflicting results might indicate: (i) the presence of counterbalancing positive and negative effects on kidney function of both serum uric acid and urate-lowering agents, (ii) the presence of a subpopulation of patients, as yet unidentified, which could truly benefit from a urate-lowering therapy. Therefore, today the treatment of asymptomatic hyperuricemia is not recommended nor excluded by current guidelines. Here we suggest that a possible guide for the treatment of asymptomatic hyperuricemia might be the presence of urate crystals in the urine sediment and/or signs of asymptomatic articular damage by urates, identified by musculo-skeletal ultrasound. Moreover, a watchful analysis of the trend in creatinine/eGFR, proteinuria or urate levels might also guide the clinician. Initiation of ULT and follow-up in cases of asymptomatic hyperuricemia should consider urine sediment analysis, musculoskeletal ultrasound and trends in creatinine, proteinuria and serum urate levels.




\section{Kidney Blood Pressure Research}

Kidney Blood Press Res 2018;43:606-615

\begin{tabular}{l|l}
\hline DOI: 10.1159/000489145 & (C) 2018 The Author(s). Published by S. Karger AG, Basel
\end{tabular}

Published onlıne: 24 April, 2018

www.karger.com $/ \mathrm{kb}$

Viggiano et al.: Urine Sediment and Musculoskeletal Ultrasound in Asymptomatic

Hyperuricemia

\section{Introduction}

The use of urate-lowering drugs is still matter of controversies and of ongoing research. Current knowledge reflects a non-linear path in history with the alternation of different positions. The understanding of this path allows having a clearer picture of the uncertainty of current knowledge.

\section{Discovery of uric acid in the urine and its evolutionary meaning}

In 1776 Scheele found a substance characterizing urinary stones, which was afterwards named by Morveau "Lytic acid". In 1798, Pearson renamed the substance "uric oxide". Foucroy agreed with Pearson that the term "lytic" was inappropriate and proposed the name "uric acid", which is still in use today [1]. Uric acid is produced by the enzyme xanthine oxidase (or by xanthine dehydrogenase) from xanthine and hypoxanthine, a reaction important for the scavenging of free radicals [2]. It is degraded by urate oxidase in rodents and pigs, whereas in humans this enzyme is non-functional $[3,4]$. Interestingly, humans have lost the uricase gene together with the gene responsible for ascorbate synthesis (a potent antioxidant) [5], whereas rodents cannot loose uricase, as the deletion of urate oxidase gene is incompatible with life (as demonstrated by mouse knock-out experiments) [6]. So why humans can be spared from the need of uricase, whereas other animals need it? Possibly in humans unknown factors contribute to the stability of uric acid in blood and kidneys, thereby preventing a massive damage to the kidneys. Moreover, the increased levels of uric acid in humans might counterbalance the loss of ascorbate. Indeed, uric acid has 'protective' properties such as (i) anti-oxidant activity (possibly replacing the loss of ascorbate synthesis) $[5,7]$, (ii) antinatriuretic and vascular effects mediating blood pressure homeostasis in lowsalt environments [4], (iii) neuroprotection, particularly on dopaminergic neurons [8], (iv) modulator of the gut microbiome, whose composition is therefore different in humans from other animals $[9,10]$ a marker of effective blood volume and antidiuretic hormone levels $[11,12]$ and an accurate and reliable marker of kidney function [13].

\section{The paradigm of hyperuricemia-gout-nephropathy association}

The discovery of the link between uric acid and gout in the early 1900s' by Garrod [14] led to the concept that uric acid is a toxin responsible for arthritis. Much later, in 1960, uric acid was proposed as a toxin also for the kidney (hence called 'gouty nephropathy') [15] and for the cardiovascular system $[16,17]$. The hypothesis of uric acid as a nephrotoxic agent gained much success, possibly in wake of still ongoing research on uremic toxins [18].

The main evidences of alinkbetween gout, the disease of rich people due to hyperuricemia, and renal disease at that time are summarized below: (i) histopathology studies: in the late $19^{\text {th }}$ century Garrod showed sodium urate accumulation in the interstitium of the kidney of a patient with gout (post-mortem study) [14]. In 1952 Modern and Meister propose that renal insufficiency, normal blood pressure, without proteinuria, characterized the 'kidney of gout' in three patients [19]. In 1960 Talbott and Terplan review 279 autoptic cases of gout revealing renal lesions (pyelonephritic scars, intrarenal tophi, arterial sclerosis, interstitial fibrosis) [15]. Uric acid crystals were thought to form directly in the interstitium; (ii) pathogenetic studies: the kidney of the majority of gouty patients does not eliminate adequately uric acid, which would lead to hyper-uricemia and therefore to gout [20]. The main consequence is that the levels of uric acid would be normal in the tubules of gouty patients but likely increased in the interstitium (where urate deposits were reported). This was consonant 


\section{Kidney Blood Pressure Research}

Kidney Blood Press Res 2018;43:606-615

\begin{tabular}{l|l}
\hline DOI: $10.1159 / 000489145$ & (C) 2018 The Author(s). Published by S. Karger AG, Basel
\end{tabular}

Published onlıne: 24 April, 2018

www.karger.com/kb

Viggiano et al.: Urine Sediment and Musculoskeletal Ultrasound in Asymptomatic

Hyperuricemia

with known properties of tubules in the processing of uric acid and $\mathrm{NaCl}$ transport [21]; (iii) experimental studies on animal models: in 1974 experiments on rats treated with oxonic acid, a uricase inhibitor, showed the developed hyperuricemia, hyperuricosuria and renal disease [22].

The data seemed to support the paradigm that, in gout, uric acid would accumulate in the kidney interstitium, forming crystals and leading to kidney fibrosis and renal failure.

\section{A requiem for gouty nephropathy?}

Much like the dynamics of scientific discussions described by Kuhn [23], a number of evidences in contrast with the paradigm of a gouty nephropathy started to accumulate. Faced with these evidences, scientists proposed a revision of the paradigm and, later, its rejection. A selection of the evidences against a 'gouty nephropathy' is listed below: (i) uric acid deposits in the kidney occur without gout in $86 \%$ of patients [24]; (ii) the animal model with oxonic acid (a) does not develop arthritis (in contrast with gout), (b) shows intratubular (not interstitial) uric acid deposits and (c) presents and acute renal failure (in contrast with the human chronic disease). The results have been replicated using mice genetically lacking uricase, which die after only 4 weeks of age, with a devastating nephropathy from intratubular (not interstitial) urate crystals, very different from the human disease [6].

These findings led to an adaptation of the initial paradigm: hyperuricemia (even without gout) is a cause of kidney injury, thus accounting for the presence of kidney injury in hyperuricemic patients without gout [25]. Again, new evidences started to accumulate, contradicting also the revised paradigm: (i) since 1960 it was known a hereditary form of gout accompanied by a renal nephropathy without uric acid crystals into the kidney [26]; (ii) in 1975 Berger and Yu longitudinally studied gouty patients, showing no modification of kidney function after 11 years of follow up; however kidney function deteriorated in gouty patients with hypertension [27]. In these patients the treatment of hyperuricemia (with allopurinol) did not influence the evolution of the kidney function; (iii) in the 1980s, many patients thought to have chronic urate nephropathy were found to be actually affected by lead nephropathy [28, 29]. These data led Laurence H Beck to write in 1986 an influential paper entitled "Requiem for gouty nephropathy", where a new paradigm was therefore proposed: hyperuricemia, with or without gout, does not induce chronic renal disease and allopurinol treatment does not modify the renal destiny in chronic kidney disease [30]. However, he accepted that an acute, massive hyperuricemia (as in tumor lysis) can cause an "acute uric acid nephropathy"; at variance, gout and renal disease can coexist due to a genetic mutation, without causal relationship between gout and renal disease [31]. The new paradigm offered explanations for previous findings: (i) the old data were based on retrospective cadaveric studies and thus confused cause-effect relationship between gout and nephropathy (kidney disease causes hyperuricemia); (ii) the old retrospective data were affected by a confounding factor: many hyperuricemic subjects were hypertensive, and thus developed nephropathy due to hypertension and not because of hyperuricemia [32,33] ; (iii) moreover mice lacking uricase are not a model of gout, but actually a model of "acute uric acid nephropathy" as in tumor lysis syndrome, due to the large, acute, deposits of uric acid crystals inside tubules, thus leading to acute loss of renal function; (iv) a familial form of "urate nephropathy" (FJHN), caused by a mutation in the uromodulin gene which was responsible for the nephropathy with a consequent hyperuricemia [34]. The term "gouty nephropathy" was, therefore, abandoned and the locution "urate nephropathy" was reserved for the acute disease caused by massive hyperuricemia, such as in tumor lysis syndrome [35]. 


\section{Kidney Blood Pressure Research}

Kidney Blood Press Res 2018;43:606-615

\begin{tabular}{l|l}
\hline DOI: $10.1159 / 000489145$ & (C) 2018 The Author(s). Published by S. Karger AG, Basel
\end{tabular}

Published onlıne: 24 April, 2018

www.karger.com/kb

609

Viggiano et al.: Urine Sediment and Musculoskeletal Ultrasound in Asymptomatic

Hyperuricemia

\section{Urate-lowering therapy (ULT)}

During a drug-discovery program aimed at finding new therapies for cancer, in 1956 Robins found the first urate-lowering drug acting as an inhibitor of xanthine oxidase, named allopurinol [36, 37]. Many years later, in 1998, a new urate-lowering drug was discovered, Febuxostat, and licensed in 2008-2009 (brand name: Adenuric) [36]. Interestingly, the Pubmed database reports that, in the years 1980-2000, the number of publications in nephrology increased exponentially, whereas the papers on urate nephropathy decreased following Beck's publication. However, the trend reversed approximately after Febuxostat discovery, with a renewed interest for urate nephropathy. Furthermore, in 2002 a new uric acid lowering drug was introduced, a recombinant urate oxidase named Rasburicase (even though a similar drug, Uricozyme, was already introduced in 1975, but did not encounter much success). Rasburicase found its application in acute urate nephropathy, as in tumor lysis syndrome. In more recent times, canagliflozin, a glycosuric agent inhibiting the glucose transporter SGLT1, was also found to have uricosuric effect [38]. Incidentally, the serendipitous finding that commonly used drugs exert uricosuric effect is not new, such as in the case of losartan [39], fenofibrate [40] and more recently sevelamer [41]. Therefore, three direct acting drugs (allopurinol, febuxostat, Rasburicase) and at least four 'indirect' drugs with other important targets (canagliflozin, losartan, fenofibrate and sevelamer) are today available as urate-lowering therapy (ULT). Moreover, the alcalinization of urines (pH 8) with bicarbonate (50-150 mEq in $1 \mathrm{~L}$ of D5W i.v. 1-1.5 L/hour or 325-2000 mg per os, 1-4 times/ day) may also be implemented to dissolve urate crystals, which require acidic environment to precipitate $[42,43]$. On the flip side, several drugs are known to increase serum levels of uric acid, such as diuretics, aspirin, cyclosporine, and theophylline . Moreover, mycophenolate and ACE inhibitors are reported to induce gout in patients (incidence of $3-10 \%$ and $<1 \%$ respectively) [37, 44].

At present, there is a consensus that in cases of symptomatic hyperuricemia (gout, urate-nephrolithiasis), a ULT should be started, urine alkalinization considered and, when possible, drugs inducing hyperuricemia discontinued. Conversely, the very frequent conditions of asymptomatic hyperuricemia remain a major conundrum for the clinician, principally because, notwithstanding the Beck's Requiem, the relationship between chronic kidney disease (CKD) and hyperuricemia is still a matter of debate. A recent metanalysis conducted by Li et al. [45], based on thirteen studies, concludes that elevated serum uric acid levels represents a risk for the development of chronic renal dysfunction. However, the metanalysis did not include important 'negative' studies, such as the notable "Modification of Diet in Renal Disease" and the "Mild to Moderate Kidney Disease" studies that did not find a link between CKD and hyper-uricemia [46, 47]. Similarly, the metanalyses exploring the link between urate-lowering agents and nephroprotection are quite contrasting [48, 49]. The metanalysis by Bose et al. [48] acknowledges "substantial heterogeneity" among studies, with five trial concluding no effect of allopurinol on GFR and three trials with protective effects, with inconclusive data on the progression to end-stage kidney disease. The presence of such conflicting results raises the suspicion that, if uric acid represents an independent risk factor for CKD, (i) it does not attain to all human subjects but only to a subpopulation and/or (ii) the effect size is small (for example because negative effects of hyperuricemia are partially counterbalanced by positive effects or because urate-lowering agents have adverse effects that counterbalance the reduction of serum uric acid).

Conversely, the excessive decrease of serum uric acid should be avoided due to the increased incidence of neurodegenerative diseases in presence of low uric acid levels [50]. Indeed, uric acid is an important neuroprotective factor for dopamine neurons, thus preventing Parkinson's disease [8]. Historically, it is interesting to remember how the connection between uric acid and the brain started on a false assumption: in the early 1960s' 


\section{Kidney Blood Pressure Research}

Kidney Blood Press Res 2018;43:606-615

\begin{tabular}{l|l}
\hline DOI: $10.1159 / 000489145$ & (C) 2018 The Author(s). Published by S. Karger AG, Basel
\end{tabular}

Published onlıne: 24 April, 2018

www.karger.com/kb

iggiano et al.: Urine Sediment and Musculoskeletal Ultrasound in Asymptomatic

Hyperuricemia

the observation that men of genius are frequently troubled with gout led to the hypothesis that this was due to the similarity between uric acid and purines, thus stimulating the cerebral cortex [51]. However, the subsequent research found a significant but very low correlation between intelligence (indexed by the IQ) and serum uric acid levels [52-55]. Therefore, current guidelines do not recommend to treat asymptomatic hyperuricemia to slow the progression of chronic kidney disease or CKD ("There is insufficient evidence to support or refute the use of agents to lower serum uric acid concentrations in people with CKD and either symptomatic or asymptomatic hyperuricemia in order to delay progression of CKD. (Not Graded)") [56].

\section{Serum Urate and cardiovascular risk}

Notably, almost in parallel with the proposal of the gouty nephropathy hypothesis, a completely different paradigm regarding hyperuricemia was being proposed, that is a role of sodium urate in cardiovascular disease. The idea of this association routes back in the late $19^{\text {th }}$ century with Mahomed, Haig, and Davis [57]. After a long hiatus, the uric acid-cardiovascular hypothesis then is presented again around 1950 (again at the same time of the 'gouty nephropathy' hypothesis), by the work of Gertler et al. [16]. In 1999 the Framingham study supported the view that uric acid is not a risk factor for cardiovascular disease [58]. This was later confirmed by similarly large studies and metanalysis [59]. Current guidelines (e.g. JNC8) do not list uric acid as a risk factor. The main reason for this change in direction has been the strong association of uric acid levels and other known risk factors for cardiovascular disease (obesity, diabetes etc.). Interventional studies and metanalysis about urate-lowering therapy on cardiovascular disease do not support this approach to reduce cardiovascular risk [60]. A previous Cochrane review reached the same result, even though it is possible that urate-lowering approach might have an effect on hypertension [61]. Overall, the association between uric acid and cardiovascular disease appear to have the same dynamic of gouty nephropathy. As proposed at the end of the discussion, it is possible that the alternating positions towards this paradigm underline a difficulty to identify a subpopulation that would truly benefit from urate-lowering therapy.

\section{Hints to start a urate-lowering therapy (ULT)}

The possibility to identify a subpopulation of subjects particularly prone to urate damage would allow to use urate-lowering agents only on subjects that would really benefit from them. Here we propose to identify subjects at high risk of CKD progression from urates by analyzing (i) the urinary sediment (ii) musculoskeletal ultrasound (iii) longitudinal study of CKD progression rate (Fig. 1). Specifically, urinary sediment should be interrogated for the presence of urate crystals, which would demonstrate supra-saturating levels of uric acid in the kidney. Similarly, the musculo-skeletal ultrasound can identify signs of urate deposition on joints far before any sign of gout is evident at clinical level [62].

Case reports and case series support this claim. Randall reported the presence of uric acid crystals in the urine sediment of a patient with ileostomy with progressive kidney damage, who responded to an oral sodium bicarbonate therapy [42]. A familial form of hyperuricosuria and hematuria, which responded to a therapy with allopurinol, diuretics and fluid intake, was also identified by uric acid crystals in the urine sediment [63]. Moreover, the presence of urate crystals in urine sediment has been identified in the case of Mesoamerican nephropathy [64].

On the other side, asymptomatic urate deposition in joints can be recognized using ultrasound (MSK-US), such as hyperechoic enhancement of the cartilage surface, the double contour image of the cartilage, intra-articular hyperechoic clouds, bone erosion, synovitis, 


\section{Kidney Blood Pressure Research}

Viggiano et al.: Urine Sediment and Musculoskeletal Ultrasound in Asymptomatic Hyperuricemia

periarticular power signal $[62,65]$. These signs precede articular symptoms (so called 'hidden gout'). The sensitivity/specificity of US in identifying gout in symptomatic patients is quite high: 83\%/82\% according to Löffler et al. [66], $87.2 \% / 84 \%$ according to Bhadu et al. [67], $84 \% / 81 \%$ in early gout [68]respectively. In pre-gout (hidden gout), asymptomatic patients, no sensitivity/specificity exists formally because, in this

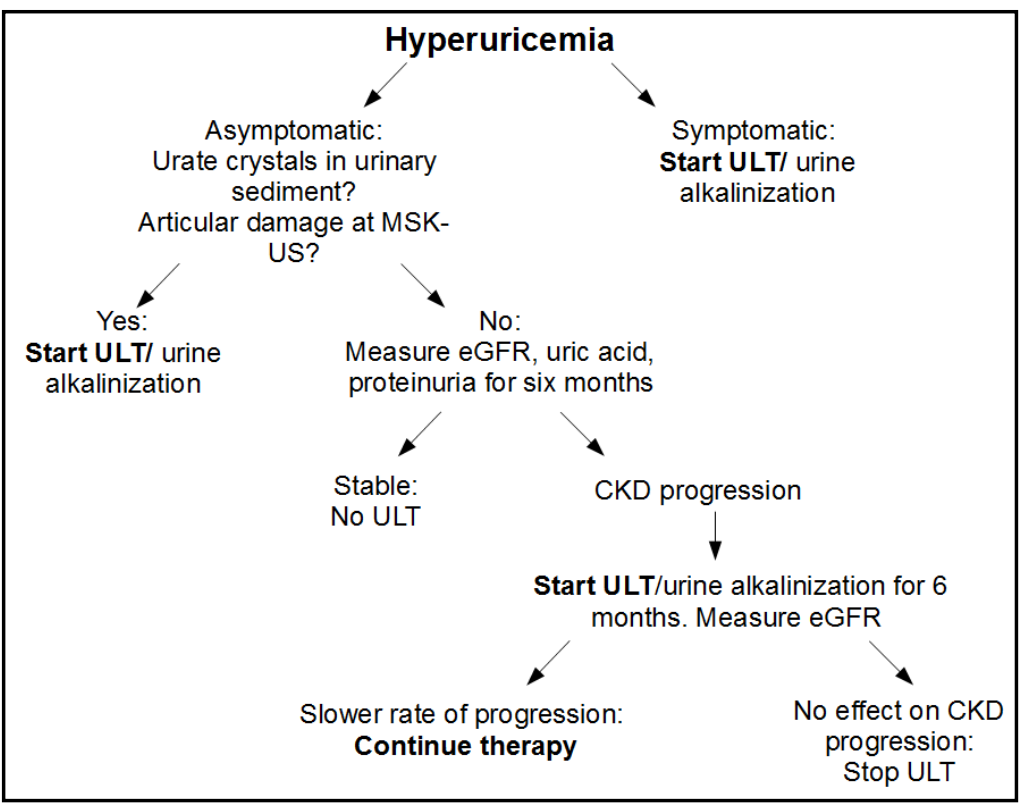

Fig. 1. Proposed algorithm to initiate urate-lowering therapy (ULT). population, there is no gold standard to compare with. However, we know that $13 \%$ of asymptomatic, hyperuricemic patients have identifiable ultrasound modifications on the first metatarsophalangeal joint, whereas only $7 \%$ of the normal population shows US abnormalities [69].

In the absence of clear directions for treatment of asymptomatic hyperuricemia, it is reasonable to start ULT in patients with urate precipitates in urines (recognized in the sediment) and in joints (recognized by ultrasound). Therefore, we recommend that research for urate crystals in urine sediment and musculo-skeletal ultrasound (MSK-US) are carried out, as an indication to start ULT and as a follow-up to verify that adequate levels of serum uric acid have been reached.

Finally, another reasonable approach in hyperuricemic patients without signs of urate crystals in urine or MSK-US is a watchful observation of the CKD progression rate (using eGFR, proteinuria or the same levels of serum uric acid) over a period of at least 6-months. Given the absence of data concerning the rate of GFR alterations in hyperuricemic patients, we suggest that in this population controls of serum creatinine should be performed every six months. The measurement of the kidney residual function might also be taken into consideration [70]. If the kidney function is stable and no signs of urates precipitation in urine and joints can be evidences, the clinician might consider to postpone ULT. Vice-versa, in presence of deteriorating kidney function, a challenge with ULT/urine alkalinization may be used and the efficacy evaluated for a minimum of 6 months. If no effect on CKD progression rate is observed, ULT is unlikely to be beneficial for the patient (Fig. 1).

The use of urate-lowering agent should be reserved to high-risk subpopulation, because their use potentially depletes the patient from a neuroprotective factor and reduces the possibility to use uric acid as a marker of kidney function. One possibility to identify a subpopulation of subjects particularly prone to urate damage might be the finding of urate crystals in urine sediment and ultrasound alterations in a musculo-skeletal ultrasound; a challenge with ULT and urine alkalinization is warranted in cases with signs of CKD progression, using as a feedback for the efficacy of the intervention a change in CKD progression rate. 


\section{Kidney \\ Blood Pressure Research}

Kidney Blood Press Res 2018;43:606-615

\begin{tabular}{|l|l|}
\hline DOI: $10.1159 / 000489145$ & (c) 2018 The Author(s). Published by S. Karger AG, Basel \\
\hline
\end{tabular}

Published online: 24 April, 2018

www.karger.com/kbr

Hyperuricemia

\section{Conclusion}

Treatment of asymptomatic hyperuricemia is not recommended by current guidelines. However, by using urine sediment analysis and musculo-skeletal ultrasound it might be possible to identify a subpopulation of patients which might benefit from urine-lowering agents. Both methods might be also used in the follow-up to verify the therapeutic results.

\section{Disclosure Statement} article.

The authors declare they have no conflicts of interest regaridng the publication of this

\section{References}

1 Thomson T: Chemistry of Animal Bodies. Edinburgh, p. 31, 1858.

2 Viggiano AA, Viggiano D, Viggiano AA, De Luca B: Quantitative histochemical assay for superoxide dismutase in rat brain. J Histochem Cytochem 2003;51:1-7.

3 Wu X, Muzny D, Lee C, Caskey C: Two independent mutational events in the loss of urate oxidase during hominoid evolution. J Mol Evol 1992;34:78-84.

4 Watanabe S, Kang D-H, Feng L, Nakagawa T, Kanellis J, Lan H, Mazzali M, Johnson RJ: Uric acid, hominoid evolution, and the pathogenesis of salt-sensitivity. Hypertension 2002;40:355-360.

5 Ames BN, Cathcart R, Schwiers E, Hochstein P: Uric acid provides an antioxidant defense in humans against oxidant- and radical-caused aging and cancer: A hypothesis. Proc Natl Acad Sci U S A 1981;78:6858-6862.

6 Wu X, Wakamiya M, Vaishnav S, Geske R, Montgomery C, Jones P, Bradley A, Caskey CT: Hyperuricemia and urate nephropathy in urate oxidase- deficient mice. Proc Natl Acad Sci USA 1994;91:742-746.

7 Sautin YY, Johnson RJ: Uric acid: the oxidant-antioxidant paradox. Nucleosides Nucleotides Nucleic Acids 2008;27.

8 Chen X, Burdett TC, Desjardins CA, Logan R, Cipriani S, Xu Y, Schwarzschild MA: Disrupted and transgenic urate oxidase alter urate and dopaminergic neurodegeneration. Proc Natl Acad Sci 2013;110:2-7.

-9 Shao T, Shao L, Li H, Xie Z, He Z, Wen C: Combined Signature of the Fecal Microbiome and Metabolome in Patients with Gout. Front Microbiol 2017;8:268.

10 Guo Z, Zhang J, Wang Z, Ang KY, Huang S, Hou Q, Su X, Qiao J, Zheng Y, Wang L, Koh E, Danliang H, Xu J, Lee YK, Zhang H: Intestinal Microbiota Distinguish Gout Patients from Healthy Humans. Sci Rep 2016;6:20602.

11 Taniguchi K, Tamura Y, Kumagai T, Shibata S, Uchida S: Stimulation of V1a receptor increases renal uric acid clearance via urate transporters: insight into pathogenesis of hypouricemia in SIADH. Clin Exp Nephrol 2016;20:845-852.

12 Zacchia M, Di Iorio V, Trepiccione F, Caterino M, Capasso G: The Kidney in Bardet-Biedl Syndrome: Possible Pathogenesis of Urine Concentrating Defect. Kidney Dis 2017;3:57-65.

$>13$ Nigro M, Viggiano D, Ragone V, Trabace T, Di Palma A, Rossini M, Capasso G, Gesualdo L, Gigliotti G: A crosssectional study on the relationship between hematological data and quantitative morphological indices from kidney biopsies in different glomerular diseases. BMC Nephrol 2018;19:62.

14 Garrod A: The nature and treatment of gout and rheumatic gout, ed 2, London, 1863.

15 Talbott JH, Terplan KL: The kidney in gout. Medicine (Baltimore) 1960;39:405-467.

16 Gertler M, Garn S, Levine S: Serum uric acid in relation to age and physique in health and in coronary heart disease. Ann Intern Med 1951;34:1421-1423.

17 Kohn P, Prozan G: Hyperuricemia; relationship to hypercholesteremia and acute myocardial infarction. JAMA 1959;170:1909-1912. 


\section{Kidney \\ Blood Pressure Research}

Viggiano et al.: Urine Sediment and Musculoskeletal Ultrasound in Asymptomatic Hyperuricemia

18 Perna A, Di Nunzio A, Amoresano A, Pane F, Fontanarosa C, Pucci P, Vigorito C, Cirillo G, Zacchia M, Trepiccione F, Ingrosso D: Divergent behavior of hydrogen sulfide pools and of the sulfur metabolite lanthionine, a novel uremic toxin, in dialysis patients. Biochimie 2016;126:97-107.

19 Modern FW, Meister L: The kidney of gout, a clinical entity. Med Clin North Am 1952;21:941-951.

-20 Rieselbach RE, Sorensen LB, Shelp WD, Steele TH: Diminished renal urate secretion per nephron as a basis for primary gout. Ann Intern Med 1970;73:359-366.

21 Zacchia M, Capasso G: Parvalbumin: A Key Protein in the Early Distal Tubule NaCl Reabsorption. Nephrol Dial Transpl 2008;23:1109-1111.

-22 Waisman J, Bluestone R, Klinenberg J: A preliminary report of nephropathy in hyperuricemic rats. Lab Invest 1974;30:716-722.

23 Kuhn TS: The Structure of Scientific Revolutions. Chicago, University of Chicago Press, 1996.

-24 Linnane JW, Burry AF, Emmerson BT: Urate deposits in the renal medulla. Prevalence and associations. Nephron 1981;29:216-222.

25 Murray T, Goldberg M: Chronic interstitial nephritis: etiologic factors. Ann Intern Med 1975;82:453-459.

26 Duncan H, Dixon AS: Gout, familial hypericaemia, and renal disease. Q J Med 1960;29:127-135.

27 Berger L, Yü TF: Renal function in gout. IV. An analysis of 524 gouty subjects including long-term follow-up studies. Am J Med 1975;59:605-613.

28 Batuman V, Maesaka JK, Haddad B, Tepper E, Landy E, Wedeen RP: The role of lead in gout nephropathy. N Engl J Med 1981;304:520-523.

29 Craswell PW, Price J, Boyle PD, Heazlewood VJ, Baddeley H, Lloyd HM, Thomas BJ, Thomas BW: Chronic renal failure with gout: a marker of chronic lead poisoning. Kidney Int 1984;26:319-323.

30 Beck LH, Harrinoton JT, Kairer JP: Requiem for gouty nephropathy. Kidney Int 1986;30:280-287.

-31 Becker MA, Jolly M: Hyperuricemia and Associated Diseases. Rheum Dis Clin North Am 2006;32:275-293.

-32 Segura J, Campo C, Ruilope LM: How relevant and frequent is the presence of mild renal insufficiency in essential hypertension? J Clin Hypertens 2002;4:332-336.

-33 Petrazzuolo 0, Trepiccione F, Zacchia M, Capasso G: Hypertension and renal calcium transport. J Nephrol 2010;23:S112-S117.

-34 Dahan K, Devuyst O, Smaers M, Vertommen D, Loute G, Poux J-M, Viron B, Jacquot C, Gagnadoux MF, Chauveau D, Büchler M, Cochat P, Cosyns JP, Mougenot B, Rider MH, Antignac C, Verellen-Dumoulin C, Pirson Y: A cluster of mutations in the UMOD gene causes familial juvenile hyperuricemic nephropathy with abnormal expression of uromodulin. J Am Soc Nephrol 2003;14:2883-2893.

35 Lusco MA, Fogo AB, Najafian B, Alpers CE: AJKD Atlas of Renal Pathology: Gouty Nephropathy. Am J Kidney Dis 2017;69:e5-e6.

36 Robins RK: Potential Purine Antagonists. I. Synthesis of Some 4, 6-Substituted Pyrazolo [3, 4-d] pyrimidines. J Am Chem Soc 1956;78:784-790.

37 Pacher P, Nivorozhkin A, Szabó C: Therapeutic Effects of Xanthine Oxidase Inhibitors: Renaissance Half a Century after the Discovery of Allopurinol. Pharmacol Rev 2006;58:87-114.

-38 Davies MJ, Trujillo A, Vijapurkar U, Damaraju CV, Meininger G: Effect of canagliflozin on serum uric acid in patients with type 2 diabetes mellitus. Diabetes Obes Metab 2015;17.

-39 Nakashima M, Uematsu T, Kosuge K, Kanamaru M: Pilot study of the uricosuric effect of DuP-753, a new angiotensin II receptor antagonist, in healthy subjects. Eur J Clin Pharmacol 1992;42:333-335.

40 Desager JP, Hulhoven R, Harvengt C: Uricosuric effect of fenofibrate in healthy volunteers. J Clin Pharmacol 1980;20:560-564.

41 Garg JP, Chasan-Taber S, Blair A, Plone M, Bommer J, Raggi P, Chertow GM: Effects of sevelamer and calciumbased phosphate binders on uric acid concentrations in patients undergoing hemodialysis: a randomized clinical trial. Arthritis Rheum 2005;52:290-295.

42 Randall Jr RE: Urate Nephropathy following Chronic Ileostomy Acidosis. Am J Nephrol 2002;22:372-375.

43 Ngo TC, Assimos DG: Uric Acid nephrolithiasis: recent progress and future directions. Rev Urol 2007;9:1727.

44 Ben Salem C, Slim R, Fathallah N, Hmouda H: Drug-induced hyperuricaemia and gout. Rheumatology 2016;56:679-688. 


\section{Kidney \\ Blood Pressure Research}

Kidney Blood Press Res 2018;43:606-615

\begin{tabular}{l|l}
\hline DOI: $10.1159 / 000489145$ & (C) 2018 The Author(s). Published by S. Karger AG, Basel
\end{tabular}

Published onlıne: 24 April, 2018 www.karger.com/kbr

Hyperuricemia

45 Li L, Yang C, Zhao Y, Zeng X, Liu F, Fu P: Is hyperuricemia an independent risk factor for new-onset chronic kidney disease?: a systematic review and meta-analysis based on observational cohort studies. BMC Nephrol 2014;15:122.

-46 Sturm G, Kollerits B, Neyer U, Ritz E, Kronenberg F, MMKD Study Group: Uric acid as a risk factor for progression of non-diabetic chronic kidney disease? The Mild to Moderate Kidney Disease (MMKD) Study. Exp Gerontol 2008;43.

47 Madero M, Sarnak MJ, Wang X, Greene T, Beck GGJ, Kusek JW, Collins AJ, Levey AS, Menon V: Uric acid and long-term outcomes in CKD. Am J Kidney Dis 2009;53:796-803.

-48 Bose B, Badve SV, Hiremath SS, Boudville N, Brown FG, Cass A, de Zoysa JR, Fassett RG, Faull R, Harris DC, Hawley CM, Kanellis J, Palmer SC, Perkovic V, Pascoe EM, Rangan GK, Walker RJ, Walters G, Johnson DW: Effects of uric acid-lowering therapy on renal outcomes: a systematic review and meta-analysis. Nephrol Dial Transplant 2014;29:406-413.

-49 Kanji T, Gandhi M, Clase CM, Yang R: Urate lowering therapy to improve renal outcomes in patients with chronic kidney disease: systematic review and meta-analysis. BMC Nephrol 2015;16:58.

50 Alvarez-Lario B, MacArron-Vicente J: Is there anything good in uric acid? QJM 2011;104:1015-1024.

51 Stetten DJ: Gout. Perspect Biol Med 1959;2:185-196.

52 Montoye HJ, Mikkelsen WM: Serum Uric Acid and Achievement in High School. Arthritis Rheum 1973;16:359-362.

53 Stetten D, Hearon JZ: Intellectual level measured by army classification battery and serum uric acid concentration. Science 1959;129:1737.

54 Bloch S, Brackenridge CJ: Psychological, performance and biochemical factors in medical students under examination stress. J Psychosom Res 1972;16:25-33.

-55 Brooks GW, Mueller E: Serum urate concentrations among university professors; relation to drive, achievement, and leadership. JAMA 1966;195:415-418.

56 Members KB: KDIGO 2012 Clinical Practice Guideline for the Evaluation and Management of Chronic Kidney Disease. Kidney Int Suppl 2013;3:5-14.

-57 Feig DI, Kang D-H, Johnson R: Uric Acid and Cardiovascular Risk. N Engl J Med 2008;359:1811-1821.

58 Culleton B, Larson M, Kannel W, Levy D: Serum uric acid and risk for cardiovascular disease and death: the Framingham Heart Study. Ann Intern Med 1999;131:7-13.

59 Wheeler JG, Juzwishin KDM, Eiriksdottir G, Gudnason V, Danesh J: Serum Uric Acid and Coronary Heart Disease in 9,458 Incident Cases and 155,084 Controls: Prospective Study and Meta-Analysis. PLoS Med 2005;2:e76.

60 Zhang T, Pope J: Cardiovascular effects of urate-lowering therapies in patients with chronic gout: a systematic review and meta-analysis. Rheumatol 2017;56:1144-1153.

61 Gois P, Souza E: Pharmacotherapy for hyperuricemia in hypertensive patients. Cochrane Database Syst Rev 2013;1:CD008652.

62 Reuss-Borst MA, Pape CA, Tausche AK: Hidden gout- Ultrasound findings in patients with musculo-skeletal problems and hyperuricemia. Springerplus 2014;3:592.

63 Praga M, Alegre R, Hernández E, Morales E, Domínguez-Gil B, Carreño A, Andrés A: Familial microscopic hematuria caused by hypercalciuria and hyperuricosuria. Am J Kidney Dis 2000;35:141-145.

-64 Roncal-Jimenez C, García-Trabanino R, Barregard L, Lanaspa MA, Wesseling C, Harra T, Aragón A, Grases F, Jarquin ER, González MA, Weiss I, Glaser J, Sánchez-Lozada LG, Johnson RJ: Heat Stress Nephropathy From Exercise-Induced Uric Acid Crystalluria: A Perspective on Mesoamerican Nephropathy. Am J Kidney Dis 2016;67:20-30.

65 Fodor D, Nestorova R, Vlad V, Micu M: The place of musculoskeletal ultrasonography in gout diagnosis. Med Ultrason 2014;16:336-344.

-66 Löffler C, Sattler H, Löffler U, Krämer B, Bergner R: Size matters: observations regarding the sonographic double contour sign in different joint sizes in acute gouty arthritis. Z Rheumatol 2018; DOI:10.1007/ s00393-018-0425-6.

67 Bhadu D, Das S, Wakhlu A, Dhakad U, Sharma M: Ultrasonographic detection of double contour sign and hyperechoic aggregates for diagnosis of gout: two sites examination is as good as six sites examination. Int J Rheum Dis 2018;21:523-531. 


\section{Kidney Blood Pressure Research}

Viggiano et al.: Urine Sediment and Musculoskeletal Ultrasound in Asymptomatic Hyperuricemia

68 Norkuviene E, Petraitis M, Apanaviciene I, Virviciute D, Baranauskaite A: An optimal ultrasonographic diagnostic test for early gout: A prospective controlled study. J Int Med Res 2017;45:1417-1429.

69 Reuss-Borst M, Pape C, Tausche A: Hidden gout- Ultrasound findings in patients with musculo-skeletal problems and hyperuricemia. Springerplus 2014;3:592.

70 Anastasio P, Viggiano D, Zacchia M, Altobelli C, Capasso G, De Santo N: Delay in Renal Hemodynamic Response to a Meat Meal in Severe Obesity. Nephron 2017;136:151-157. 